discontinuities or layering. Mr Koo states that his average strength parameters, as calculated by his probability function, relate to specific predetermined slip surfaces. It is vital that these values are not considered to be appropriate for other surfaces. Thus we suggest that the term 'average shear strength' be dropped and 'operational shear strength' be used. Additionally the Paper stated on more than one occasion that the estimates of soil properties given are not to be used in design. They are intended only to assist in the choice of test methods and analytical techniques. For this reason the estimates are derived by relatively simple methods. The use of more complex methods is not recommended as they tend to add more value to the estimates than we feel they deserve and there is also more danger of their use in design calculations.

\title{
Consolidation of unsaturated soils including swelling and collapse behaviour
}

\author{
A. LLORET and E. E. ALONSO (1980). Géotechnique 30, No. 4, 449-477
}

\section{G. Fredlund, University of Saskatchewan}

The Authors have undertaken the development of a formulation for a difficult problem, namely the analysis of the consolidation and swelling behaviour of an unsaturated soil. In addition to the formulation, the partial differential equations were solved using the finite element numerical method. However, it appears that their formulation has been derived without awareness of similar formulations in other research publications (Hasan \& Fredlund, 1977; Fredlund \& Hasan, 1979; Dakshanamurthy \& Fredlund, 1980). On the one hand, this may seem unfortunate, but on the other the similarity with an already published formulation is encouraging. I wish to comment on significant similarities and differences in the formulations.

The starting pivotal point of both formulations is the same description of the stress state. Two independent stress state variables are used to describe the volume change behaviour of an unsaturated soil. These are $\left(\sigma-p_{\mathrm{a}}\right)$ and $\left(p_{\mathrm{a}}-p_{\mathrm{w}}\right)$ where $\sigma$ is total stress, $p_{\mathrm{a}}$ is pore-air pressure and $p_{\mathrm{w}}$ is pore-water pressure (Fredlund \& Morgenstern, 1976).

The continuity requirement used in both formulations is the same. The requirement states that the soil structure volume change of a deformable, unsaturated soil must equal the sum of the change in volume of the air and water phases due to compression or flow from the element (Fredlund, 1974). The volumetric requirement can be satisfied by the use of either a referential or a spatial type of element. The Lloret \& Alonso (1980) formulation uses the latter type, while the Fredlund \& Hasan (1979) formulation uses the former. Either type of element will yield the same end result. The continuity requirement also shows that it is necessary independently to satisfy both air and water phase continuity. This, in turn, gives rise to the need for two independent partial differential equations, one for the water phase and one for the air phase. As the objective of the analysis is to predict the dissipation of the pore-water and poreair pressures with time, it is necessary to have two equations.

Constitutive equations are required for two volume-weight properties. Lloret \& Alonso (1980) use the procedure proposed by Matyas \& Radhakrishna (1968) which independently relates void ratio and degree of saturation to both of the independent stress state variables, i.e. $\left(\sigma-p_{\mathrm{a}}\right)$ and $\left(p_{\mathrm{a}}-p_{\mathrm{w}}\right)$. Spline functions are used to approximate the three-dimensional constitutive surfaces. Fredlund \& Morgenstern (1976) proposed and experimentally verified constitutive equations for an unsaturated soil. The equations were written in the form of the volume change associated with the overall soil structure, the water phase and the air phase. The general form of the constitutive equation for the strain $\varepsilon$ for the soil structure is

$$
\varepsilon=\frac{1}{v} \frac{\partial v}{\partial\left(\sigma-p_{\mathrm{a}}\right)} \mathrm{d}\left(\sigma-p_{\mathrm{a}}\right)+\frac{1}{v} \frac{\partial v}{\partial\left(p_{\mathrm{a}}-p_{\mathrm{w}}\right)} \mathrm{d}\left(p_{\mathrm{a}}-p_{\mathrm{w}}\right)
$$

where

$$
\begin{aligned}
& v=\text { unit volume } \\
& \frac{1}{v} \frac{\partial v}{\partial\left(\sigma-p_{\mathrm{a}}\right)}=\begin{array}{l}
\text { compressibility of the soil } \\
\text { structure when } \mathrm{d}\left(p_{\mathrm{a}}-p_{\mathrm{w}}\right) \text { is } \\
\text { zero }
\end{array} \\
& \frac{1}{v} \frac{\partial v}{\partial\left(p_{\mathrm{a}}-p_{\mathrm{w}}\right)}=\begin{array}{l}
\text { compressibility of the soil } \\
\text { structure when } \mathrm{d}\left(\sigma-p_{\mathrm{a}}\right) \text { is } \\
\text { zero }
\end{array}
\end{aligned}
$$

The water phase constitutive relation describes the 
volume of water in the referential element $\theta_{w}$ in relation to the stress state

$$
\theta_{\mathrm{w}}=\frac{1}{v} \frac{\partial v_{\mathrm{w}}}{\partial\left(\sigma-p_{\mathrm{a}}\right)} \mathrm{d}\left(\sigma-p_{\mathrm{a}}\right)+\frac{1}{v} \frac{\partial v_{\mathrm{w}}}{\partial\left(p_{\mathrm{a}}-p_{\mathrm{w}}\right)} \mathrm{d}\left(p_{\mathrm{a}}-p_{\mathrm{w}}\right)
$$

where

$$
\begin{aligned}
& v_{\mathrm{w}}=\begin{array}{c}
\text { volume of water in the } \\
\text { clement }
\end{array} \\
& \frac{1}{v} \frac{\partial v_{\mathrm{w}}}{\partial\left(\sigma-p_{\mathrm{a}}\right)}=\begin{array}{l}
\text { slope of the water volume } \\
\text { against }\left(\sigma-p_{\mathrm{a}}\right) \text { plot when }
\end{array} \\
& \mathrm{d}\left(p_{\mathrm{a}}-p_{\mathrm{w}}\right) \text { is zero } \\
& \frac{1}{v} \frac{\partial v_{\mathrm{w}}}{\partial\left(p_{\mathrm{a}}-p_{\mathrm{w}}\right)}=\begin{array}{l}
\text { slope of the water volume } \\
\text { against }\left(p_{\mathrm{a}}-p_{\mathrm{w}}\right) \text { plot when }
\end{array} \\
& \mathrm{d}\left(\sigma-p_{\mathrm{a}}\right) \text { is zero }
\end{aligned}
$$

The change in volume of air present in an element can be written as the difference between the soil structure volume change and the change in the volume of water present in the element. In other words, it is possible also to write a constitutive equation for the air phase, noting that only two of the three constitutive equations are independent. The non-linear compressibilities used in equations (1) and (2) were assumed to be constants in the consolidation and swelling formulations proposed by Fredlund \& Hasan (1979).

Darcy's flow has been used to describe flow in the water phase in both the Lloret \& Alonso (1980) formulation and the Fredlund \& Hasan (1979) formulation. A similar flow law was used for the air phase in the Lloret \& Alonso formulation, while the Fredlund \& Hasan formulation used Fick's law. The two formulations are essentially the same with respect to flow laws. The coefficients of air and water permeability were assumed as constants in the Fredlund \& Hasan formulation. During the solution of the partial differential equations by a numerical technique, the coefficients of permeability could be adjusted as necessary.

The two formulations differ on assumptions regarding the solution of air in the water phase. This effect is difficult to model accurately but should not significantly affect the results as the initial and final pore-air pressure will be equal for most practical problems.

The effect of external undrained loading has been modelled as an independent change in boundary condition in the Fredlund \& Hasan (1979) formulation. In other words, a change in load induces a change in the pore-air and porewater pressures which can be described in terms of the pore pressure parameters (Hasan \& Fredlund, 1980)

$$
\begin{aligned}
& B_{\mathrm{a}}=\Delta p_{\mathrm{a}} / \Delta \sigma \\
& B_{\mathrm{w}}=\Delta p_{\mathrm{w}} / \Delta \sigma
\end{aligned}
$$

where

$$
\begin{aligned}
& B_{\mathrm{a}}=\text { pore-air pore pressure parameter } \\
& B_{\mathrm{w}}=\text { pore-water pore pressure parameter }
\end{aligned}
$$

The derivation of the pore pressure parameter requires the equations of compressibility for airwater mixtures (Fredlund, 1976).

The equations associated with the Fredlund \& Hasan (1979) formulation are consistent in form with the equations used for the saturated soil consolidation theory and demonstrate a smooth transition from the unsaturated to the saturated state. The final partial differential equation for the pore-water phase is

where

$$
\partial p_{\mathrm{w}} / \partial t=-C_{\mathrm{w}}\left(\partial p_{\mathrm{a}} / \partial t\right)+c_{\mathrm{v}}{ }^{\mathrm{w}}\left(\partial^{2} p_{\mathrm{w}} / \partial y^{2}\right)
$$

$$
\begin{aligned}
C_{\mathrm{w}}= & \text { an interactive constant associated } \\
& \text { with the water phase equation. It } \\
& \text { consists of a combination of the } \\
& \text { compressibility moduli for the un- } \\
& \text { saturated soil } \\
c_{\mathrm{v}}{ }^{\mathrm{w}}= & \text { coefficient of consolidation for the } \\
& \text { water phase } \\
t= & \text { time } \\
y= & \text { vertical spatial co-ordinate }
\end{aligned}
$$

The partial differential equation for the pore-air phase is

where

$$
\partial p_{\mathrm{a}} / \partial t=-C_{\mathrm{a}}\left(\partial p_{\mathrm{w}} / \partial t\right)+c_{\mathrm{v}}{ }^{\mathrm{a}}\left(\partial^{2} p_{\mathrm{a}} / \partial y^{2}\right)
$$

$$
\begin{aligned}
C_{\mathrm{a}}= & \text { an interactive constant associated } \\
& \text { with the air phase equation. It con- } \\
& \text { sists of compressibility moduli, pore- } \\
& \text { air pressure and volume weight } \\
& \text { properties } \\
c_{\mathrm{v}}{ }^{\mathrm{a}}= & \text { coefficient of consolidation with } \\
& \text { respect to the air phase. Both } C_{\mathrm{a}} \text { and } \\
& c_{\mathrm{v}}{ }^{\mathrm{a}} \text { contain a pore-air pressure term, } \\
& \text { and therefore, incorporate some non- } \\
& \text { linearity }
\end{aligned}
$$

Equations (5) and (6) must be solved simultaneously to give the dissipation of pore-air and pore-water pressure with time. The solution was obtained using a finite difference technique. The above equations are formulated for one-dimensional conditions; however, all the physical relations are available to extend the formulation to two-dimensional conditions (Fredlund, 1979; Dakshanamurthy \& Fredlund, 1980).

\section{REFERENCES}

Dakshanamurthy, V. \& Fredlund, D. G. (1980). Moisture and air flow in an unsaturated soil. Proc. 4th Int Conf. Expansive Soils, Denver, Colorado.

Fredlund, D. G. (1974). Engineering approach to soil continua. Proceedings of the 2nd symposium on the application of solid mechanics, McMaster University, Hamilton, Ontario, 46-59. 
Fredlund, D. G. (1976). Density and compressibility characteristics of air-water mixtures. Can. Geotech. J 13, No. 4, 386-396.

Fredlund, D. G. (1979). Appropriate concepts and technology for unsaturated soils. Can. Geotech. J. 16, No. 1, 121-139.

Fredlund, D. G. \& Hasan, J. (1979). One-dimensional consolidation theory: unsaturated soils. Can. Geotech. $J$. 16, No. 3, 521-531.

Fredlund, D. G. \& Morgenstern, N. R. (1976). Constitutive relations for volume change in unsaturated soils. Can. Geotech. J. 13, No. 3, 261-276.

Hasan, J. \& Fredlund, D. G. (1977). Consolidation theory for unsaturated soils. Symposium on water movement and equilibrium in swelling soils. San Francisco: Committee on water in the unsaturated zone, Section of Hydrology of the American Geophysical Union.

Hasan, J. U. \& Fredlund, D. G. (1980). Pore-pressure parameters for unsaturated soils. Can. Geotech. J. 17, No. 3, 395-404.

\section{Authors' reply}

The formulation presented in the Paper was specifically oriented to take into account two important characteristics of the volume change behaviour of partially saturated soils, namely the highly non-linear air and water permeability and the complex swelling collapse behaviour as described by the state surfaces. Obviously any formulation of consolidation of multiphase media should start by continuity requirements for the appropriate phases. (What in the discussion is called a 'formulation [which uses] a spatial typc of element' is, rather, a fairly general integral statement of continuity of air and water mass, whereas Mr Fredlund uses in his papers locally derived relationships. The ideas are similar and well known.) From this initial step on the formulation details may represent completely different behaviours.

The influence of porosity and, especially, degree of saturation on permeabilities to air and water (Figs 8 and 12 of the Paper) is so important that any formulation which uses constant coefficients is in high risk of large departures from actual behaviour. For example, the (sudden) saturation change of the boundaries (the third example of the Paper and Figs 19-21) is of fundamental importance in the tracing of the consolidation and moisture history of a soil layer.

Independent ('effective') stress state variables such as $\sigma_{\mathrm{j}}-p_{\mathrm{a}}, \sigma_{3}-p_{\mathrm{a}}$ and $p_{\mathrm{w}}-p_{\mathrm{a}}$ (for triaxial conditions) were suggested by Jennings $\&$ Burland (1962) and Coleman (1962). Coleman proposed the following equations (isotropic stress conditions) for volume change of partially saturated soils

$$
\begin{aligned}
& -\mathrm{d} V_{\mathrm{w}} / V=-C_{11}\left(\mathrm{~d} p_{\mathrm{w}}-\mathrm{d} p_{\mathrm{a}}\right)+C_{12}\left(\mathrm{~d} \sigma-\mathrm{d} p_{\mathrm{a}}\right)(1) \\
& -\mathrm{d} V / V=-C_{21}\left(\mathrm{~d} p_{\mathrm{w}}-\mathrm{d} p_{\mathrm{a}}\right)+C_{22}\left(\mathrm{~d} \sigma-\mathrm{d} p_{\mathrm{a}}\right)(2)
\end{aligned}
$$

where $V$ and $V_{w}$ are the current overall volume of a soil element and the volume of water held by the soil. These relationships are formally identical to $\mathrm{Mr}$ Fredlund's equations (1) and (2). Coleman (1962) mentions that the $C$ parameters (compressibilities) depend on the state of stress of the soil and their history. In fact according to the experimental results of Matyas \& Radhakrishna (1968) the compressibility of the soil (in terms of $\partial n / \partial\left(\sigma-p_{\mathbf{q}}\right)$, where $n$ is the porosity) for the stresses applied ranged from $-0.36 \times 10^{-6} \mathrm{~m}^{2} / \mathrm{N}$ to $-0.02 \times 10^{-6} \mathrm{~m}^{2} / \mathrm{N}$ (two orders of magnitude); and, in terms of compressibility with respect to suction variations, $\partial n / \partial\left(p_{\mathrm{a}}-p_{\mathrm{w}}\right)$, the range is $-0.2 \times 10^{-6} \mathrm{~m}^{2} / \mathrm{N}$ to $+0.02 \times 10^{-6} \mathrm{~m}^{2} / \mathrm{N}$.

Extreme variations of this kind both of quantitative and qualitative nature are a result of the joint swelling and collapse behaviour of partially saturated soils. The work of Fredlund \& Hasan (1979) adopted constant values for these compressibilities. The implications of this assumption are best analysed using equations (1) and (2) of $\mathrm{Mr}$ Fredlund. In fact, if

$$
m_{1}=\frac{1}{v} \frac{\partial v}{\partial\left(\sigma-p_{\mathrm{a}}\right)} \quad \text { and } \quad m_{2}=\frac{1}{v} \frac{\partial v}{\partial\left(p_{\mathrm{a}}-p_{\mathrm{w}}\right)}
$$

in equation (1) then for the strain $\varepsilon$

$$
\varepsilon-m_{1} \mathrm{~d}\left(\sigma-p_{\mathrm{a}}\right)+m_{2} \mathrm{~d}\left(p_{\mathrm{a}}-p_{\mathrm{w}}\right)
$$

or

$$
\varepsilon=m_{1} \mathrm{~d}\left[\left(\sigma-p_{\mathrm{a}}\right)+\left(m_{2} / m_{1}\right)\left(p_{\mathrm{a}}-p_{\mathrm{w}}\right)\right]
$$

which explains that soil strains depend on an 'effective' stress $\left(\sigma-p_{\mathrm{a}}\right)+\left(m_{2} / m_{1}\right)\left(p_{\mathrm{a}}-p_{\mathrm{w}}\right)$ equal to the Bishop (1959) formulation with his parameter $\chi$ being represented by the ratio $m_{2} / m_{1}$ of compressibilities. Both the Bishop formulation of effective stress and the planar state surface of Fredlund \& Hasan (1979) given by equation (3) are formally similar and unable to reproduce the well-documented collapse behaviour of partially saturated soils. In addition the non-linear compressibility has a distinct effect on the settlement-time response of saturated soil (Fig. 10 of the Paper). Qualitatively similar important effects are to be expected in partially saturated soils.

We do not think that a spline representation of laboratory-determined state surfaces for volume change is very satisfactory from a conceptual point of view. More fundamental representation of the complex deformation behaviour of partially saturated soils is needed and work is now being directed towards this goal. Before more general models are available we do not agree that 'all the physical relations are available to extend the formulation to two-dimensional conditions'.

Like Mr Fredlund, we tend to believe that the 
phenomenon of air solution into the water is small for practical problems. In fact, results not presented in the Paper showed that the pressure increment ratios for undrained loading, given in Fig. 7 of the Paper, were very close to the ratios obtained in the assumption of air insolubility into the water. However, it is not, a priori, clear that the same results would apply for general transient conditions involving significant water and air transfer through the soil.

A consequence of the linearized formulation of Fredlund is the derivation of the pore parameters $B_{\mathrm{a}}$ and $B_{\mathrm{w}}$ to compute pressure increments under undrained loading. In the analysis presented in the Paper the theoretically derived after-loading degree of saturation and porosity had to be made consistent with the general state surfaces in order to get the necessary conditions for instantaneous pressure determination. A linearized surface (tangent plane) around the initial point in the state surface (not the whole surface substituted by a plane) would perhaps be useful to find explicit formulae for $p_{\mathrm{a}}$ and $p_{\mathrm{w}}$ if the applied external stress increment is small enough. In any case we believe that a better understanding and formulation of these surfaces and in fact of the overall stressstrain behaviour is needed for real progress along these lines.

\section{REFERENCES}

Bishop, A. W. (1959). The principle of effective stress. Teknik Ukeblad 39, 859-863.

Coleman, J. D. (1962). Stress strain relations for partly saturated soil. Géotechnique 12, No. 4, 348-350.

Fredlund, D. G. \& Hasan, J. (1979). One-dimensional consolidation theory: unsaturated soils. Can. Geotech. J. 13, No. 3, 261-276.

Jennings, J. E. B. \& Burland, J. B. (1962). Limitations to the use of effective stresses in partly saturated soils. Géotechnique 12, No. 2, 125-144.

Matyas, E. L. \& Radhakrishna, H. S. (1968). Volume change characteristics of partially saturated soils. Géotechnique 18, No. 4, 432-448. 